\title{
Radiated Energy from the 16 October 1999 Hector Mine Earthquake: Regional and Teleseismic Estimates
}

\author{
by Anupama Venkataraman, Luis Rivera, and Hiroo Kanamori
}

\begin{abstract}
The amount of seismic energy radiated from an earthquake is a key macroscopic parameter for understanding the physics of earthquakes. To resolve the important details of the earthquake process, we require more accurate estimates of energy than are currently available. In this study, we determine the energy radiated from the $M_{\mathrm{w}} 7.116$ October 1999 Hector Mine, California, earthquake using regional data from 67 TriNet stations. Earlier estimates of radiated energy from regional data used empirical path and station attenuation corrections. Here, we remove the path and station attenuation effects by using an empirical Green's function deconvolution. We use one foreshock and four aftershocks as empirical Green's functions and determine the source spectra. The radiated energy at each of the regional stations is computed from these source spectra. The energy estimates from the regional data are tightly clustered, with a mean estimate of $3.0 \times 10^{15} \mathrm{~J}$ and a standard deviation of $0.9 \times 10^{15} \mathrm{~J}$. To calibrate the teleseismic methods currently used, we compare the energy estimates obtained above with the energy computed using two different teleseismic methods. The first method is based on the conventional National Earthquake Information Center (NEIC) method, in which the energy flux at each station is computed by squaring and integrating the corrected velocity spectrum. In the second method, we compute Green's functions for the appropriate source structure and deconvolve these from the mainshock data to obtain the source spectrum at each station. The energy is then calculated from the source spectra. The teleseismic energy estimates have a mean of $1.8 \times 10^{15} \mathrm{~J}$ and $2.0 \times 10^{15} \mathrm{~J}$ for the two methods, respectively. The average estimate of radiated energy from teleseismic data is nearly the same as that obtained from the regional data $\left(3 \times 10^{15} \mathrm{~J}\right)$. From the mean radiated energy $\left(3 \times 10^{15} \mathrm{~J}\right)$ and moment $\left(6 \times 10^{19} \mathrm{~N} \mathrm{~m}\right)$ estimates, the energy-to-moment ratio for the Hector Mine earthquake is $5 \times 10^{-5}$.
\end{abstract}

\section{Introduction}

Radiated seismic energy is defined as the wave energy that would be transmitted to infinity if an earthquake occurred in an infinite, lossless medium (Haskell, 1964). While seismic moment $\left(M_{0}\right)$ is estimated from the long-period end of the seismic spectrum and is a static measure of the size of an earthquake, the radiated energy $\left(E_{\mathrm{R}}\right)$ is estimated from the integral of the spectrum over the entire frequency band and is a dynamic measure of the size of an earthquake. Radiated seismic energy is also an important macroscopic parameter that can be used to understand the physical processes that occur during seismic rupture. In an attempt to understand the physics of the rupture process, many recent studies focus on the determination of spatial and temporal variations of slip, estimation of critical slip (e.g., $D_{\text {c }}$ ), and fracture energy from detailed inversion of seismic waveforms (e.g., Wald and Heaton, 1994; Boatwright and Cocco, 1996; Ide and Takeo, 1997; Guatteri and Spudich, 2000; Pulido and
Irikura, 2000; Ji et al., 2002). An alternative approach is to estimate the radiated seismic energy, because it reflects the overall frictional conditions during rupture (Kanamori and Heaton, 2000). Unfortunately, these estimates are subject to large uncertainties because of the difficulty in removing source directivity and propagation path effects, thus limiting the usefulness of radiated energy for seismic source studies.

Gutenberg (1942) and Gutenberg and Richter (1956a,b) related radiated seismic energy $\left(E_{\mathrm{R}}\right)$ in ergs to surface wave magnitude $\left(M_{\mathrm{S}}\right)$ by $\log E_{\mathrm{R}}=1.5 M_{\mathrm{S}}+11.8$. Earlier studies used this empirical relation to estimate energy (e.g., Wyss and Brune, 1971). Radiated energy has also been estimated from the average pulse widths of $P$-wave arrivals for deepfocus earthquakes (Vassiliou and Kanamori, 1982) and from source-time functions determined by inversion of seismograms (Kikuchi and Fukao, 1988). With the advent of broadband networks, estimates of radiated energy by direct 
integration of velocity records improved considerably (Boatwright and Fletcher, 1984; Boatwright and Choy, 1986; Houston, 1990a; Houston and Kanamori, 1990; Kanamori et al., 1993; Singh and Ordaz, 1994; Choy and Boatwright, 1995; Winslow and Ruff, 1999). Despite the increased availability of broadband data, it has been observed that for the same earthquake the estimates of radiated energy from regional data differ from those obtained from teleseismic data by as much as a factor of 10 (Singh and Ordaz, 1994). Additionally, the ratios of the radiated energy to seismic moment, $E_{\mathrm{R}} / M_{0}$, for small earthquakes (Abercrombie, 1995) are observed to be significantly smaller than those for large earthquakes, leading some authors to suggest drastically different energy release mechanisms for small and large earthquakes (Kanamori and Heaton, 2000). The uncertainties in the currently available estimates of energy are large, however, and the differences in the $E_{\mathrm{R}} / M_{0}$ ratio between small and large earthquakes may be due to errors in the energy estimates; more tightly constrained estimates are required to understand these differences and to validate the proposed mechanisms.

In this respect, the $M_{\mathrm{w}} 7.116$ October 1999 Hector Mine, California, earthquake provides us with an excellent data set. As mentioned earlier, to obtain accurate estimates of energy we have to correct the seismic wave energy for the propagation path effects. Uncertainty in energy estimates is largely due to uncertainty in the corrections applied to remove these effects. For the Hector Mine earthquake, we overcome this difficulty by using an empirical Green's function deconvolution to estimate the source moment-rate spectrum of the Hector mainshock for the regional data. The energy estimates computed from these source moment-rate spectra are robust, and hence this event can be used as a calibration event to study radiated energy from other events.

In the first part of this study we compute the radiated energy from regional data for the Hector Mine, California, earthquake. The Hector Mine earthquake and its aftershocks were well recorded at 67 TriNet stations in southern California. The good signal-to-noise ratio of the mainshock and several aftershocks enabled the use of the empirical Green's function method to determine the source-time function. In the second part of the paper we calibrate the teleseismic methods currently used, by comparing the energy computed from the regional data to the energy computed using two different teleseismic methods.

\section{Regional Estimates of Radiated Energy}

\section{Data}

The Hector Mine earthquake and its aftershocks occurred within the dense array of TriNet (Mori et al., 1998) stations in southern California (Fig. 1). The data are archived at the Southern California Earthquake Center (SCEC) Data Center. In our analysis, we use the tangential components of the integrated acceleration records for the mainshock and broadband velocity records for the aftershocks (empirical Green's functions). Figure $2 \mathrm{a}$ shows the tangential component of the velocity record of the mainshock and one of the aftershocks (19991019122044) at station PAS. The mainshock velocity record shown in the figure is obtained by integrating the original acceleration record. We use about $150 \mathrm{sec}$ of the mainshock and aftershock data, to include almost all the $S$-wave energy.

\section{Method}

To determine the source-time function, we use five events (one foreshock and four aftershocks with $M_{\mathrm{w}}$ 2.8-4.5; see Fig. 1 and Table 1) located close to the hypocenter of the mainshock as empirical Green's functions (EGF) (Hartzell, 1978; Frankel and Kanamori, 1983; Mori and Frankel, 1990; Mori, 1993). We deconvolve the EGF record from the mainshock record to remove the path and site effects from the mainshock. Figure 2 a shows the mainshock record, the aftershock record, and the result of the deconvolution at station Pasadena (PAS). The source spectrum is obtained by dividing the mainshock amplitude spectrum by the aftershock amplitude spectrum. The raw spectra occasionally have isolated spectral holes, which probably are due to interference effects. To prevent these spectral holes from unduly influencing the estimates of the moment-rate spectrum, we smooth both the mainshock and aftershock spectra before spectral division. The smoothing is accomplished by computing a running average over a moving window of width $2 \%$ of the total frequency range. The deconvolved spectrum is scaled by the scalar moment of the EGF to give the source spectrum of the mainshock. Figure $2 b$ shows the smoothed mainshock velocity spectrum, aftershock (19991019122044) velocity spectrum, and the source spectrum obtained by the spectral division at station PAS.

The deconvolution assumes that the mainshock and EGF are located such that the path effects are almost the same for both events. For a large event like the Hector Mine earthquake, however, we have to account for the finite depth extent of the mainshock and for the uncertainty in the exact depth of the EGF events. To consider this effect, we computed synthetic spectra for a finite fault (Hisada, 1994) and for point sources at different depths using the eastern California velocity model (Jones and Helmberger, 1998). The source spectrum is scaled by the ratio of the spectrum of the finite fault to the spectrum of a point source at a given depth. Thus, we obtain depth-corrected source spectra at each depth of the point source; however, the depth correction does not change the source spectrum significantly.

Due to the finite duration of the records used in the analysis and the poor signal-to-noise ratio of the aftershock data at long periods, the absolute value of the spectral amplitude at long periods is difficult to determine. We observe that the regional moment-rate spectra become unreliable below $0.05 \mathrm{~Hz}$. To remedy this, we use a theoretical spectrum in the form $\hat{\dot{M}}(\omega)=M_{0} \omega_{\mathrm{c}}^{n} /\left(\omega^{n}+\omega_{\mathrm{c}}^{n}\right)$ that fits the teleseismic moment-rate spectrum (obtained from $\mathrm{Ji}$ et al., 


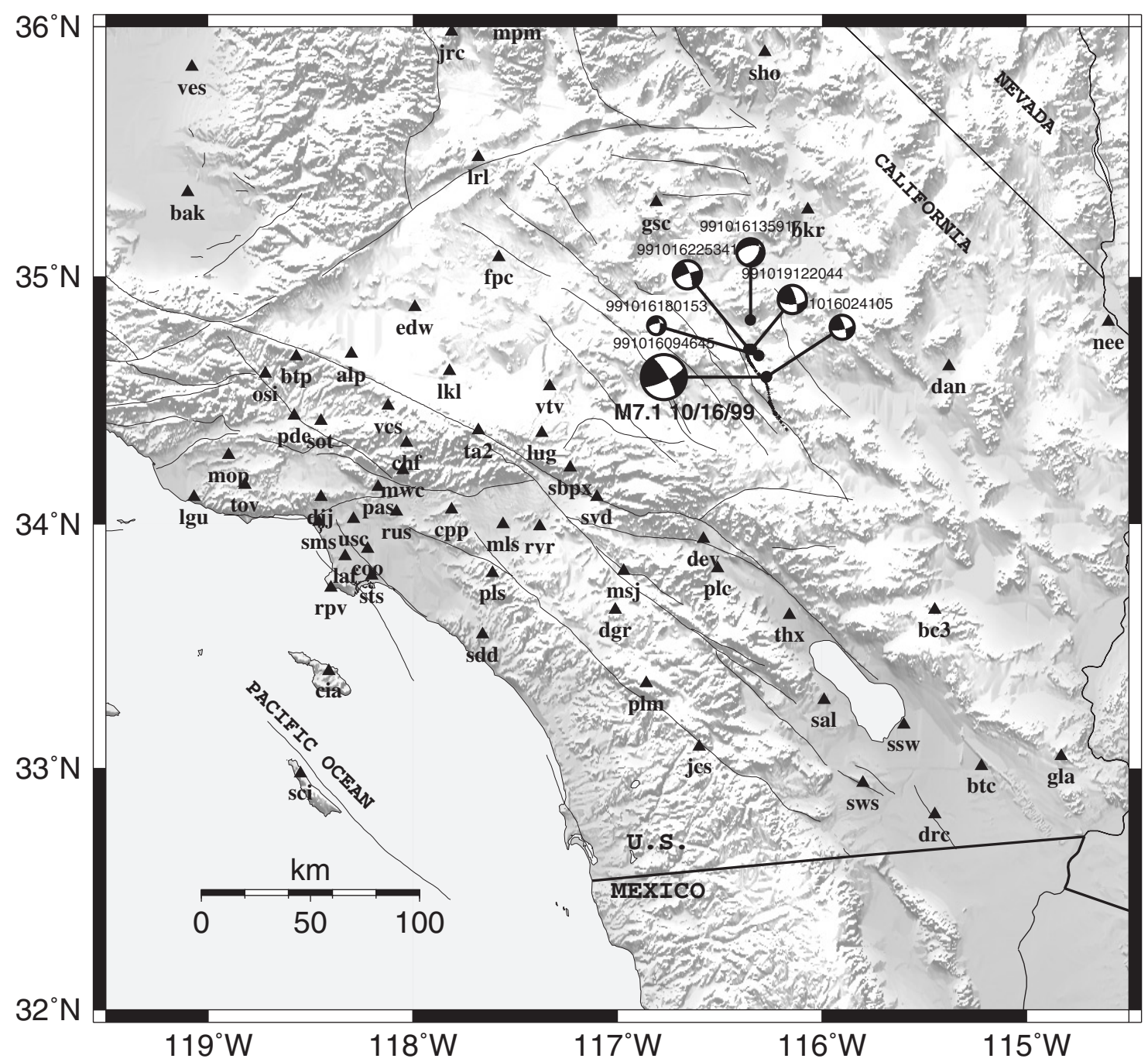

Figure 1. Location map of the $M_{\mathrm{w}} 7.116$ October 1999 Hector Mine, California, earthquake. The focal mechanisms (lower hemisphere) of the mainshock and the five empirical Green's functions (EGFs) used in the study are shown. Triangles represent seismic stations.

(2002); thin dark line shown in Fig. 3), and determine the amplitude of the theoretical spectrum at $0.05 \mathrm{~Hz}$. We then adjust the amplitude of the regional moment-rate spectrum so that its absolute amplitude at $0.05 \mathrm{~Hz}$ is the same as that of the theoretical spectrum. Figure 3 shows the raw source spectrum and average normalized source spectrum obtained by using event 19991019122044 as the EGF. There is some ambiguity in this process, but the energy mainly is determined from the regional moment-rate spectrum at each station, and teleseismic data are used only for minor adjustment.

From the source spectrum determined above, the radiated energy for a point source can be calculated using the relation (e.g., Vassilion and Kanamori, 1982)

$$
E_{\mathrm{R}}=\left(\frac{1}{15 \pi^{2} \rho \alpha^{5}}+\frac{1}{10 \pi^{2} \rho \beta^{5}}\right) \int_{0}^{\infty} \omega^{2}|\hat{\dot{M}}(\omega)|^{2} \mathrm{~d} \omega .
$$

where $\rho$ is the density, $\alpha$ is the $P$-wave velocity, and $\beta$ is the $S$-wave velocity, all in the source region, and $\hat{\dot{M}}(\omega)$ is the source spectrum. The first and second terms in the parenthesis on the right-hand side represent contributions from $P$ and $S$ waves, respectively; the $P$-wave contribution is about $5 \%$ of the $S$-wave contribution and is ignored here.

\section{Results}

We calculate the energy using equation (1) for $\rho=2.7$ $\mathrm{g} / \mathrm{cm}^{3}$ and $\beta=3.3 \mathrm{~km} / \mathrm{sec}$ for each depth of the EGF. Figure 4 shows the energy estimated from all the stations for each EGF. The aftershock records at nodal stations and at stations that are at more than $200 \mathrm{~km}$ away from the source have poorer signal-to-noise ratios. The open circles represent the energy at these stations and show a larger scatter than the closed circles. The mean estimate of radiated seismic energy computed using the values at the selected stations (closed 
(a)

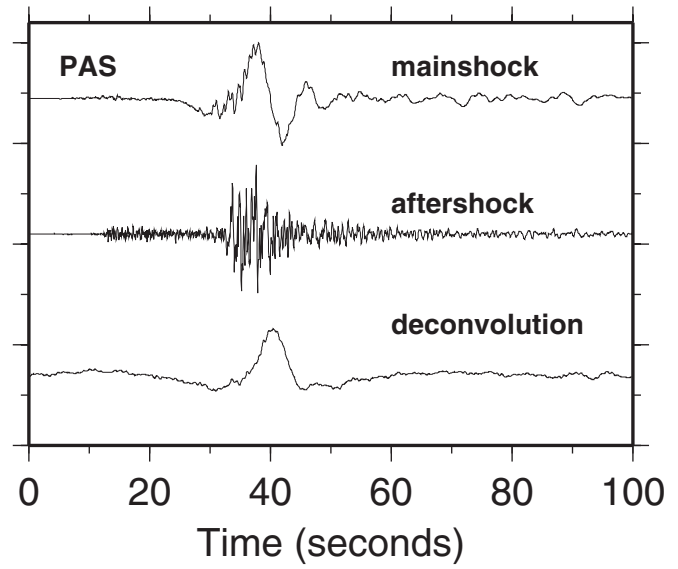

(b)

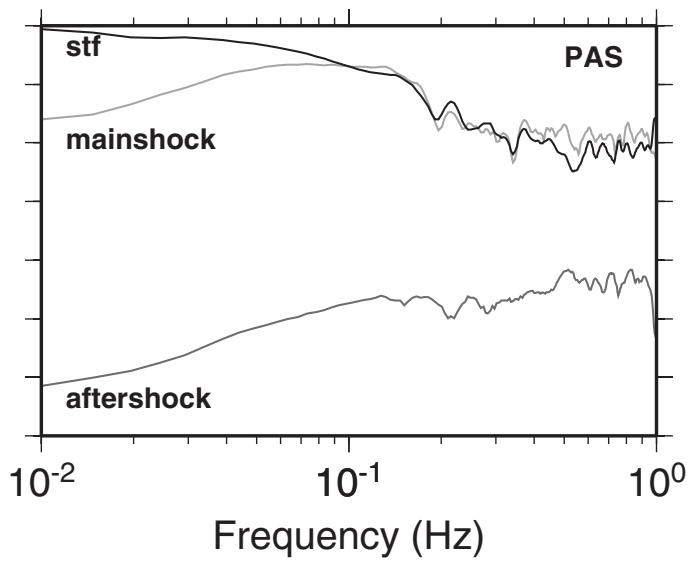

Figure 2. Results of EGF deconvolution: (a) velocity records of the mainshock and aftershock (19991019122044) and the source time function obtained by deconvolution at station PAS; (b) velocity spectra of the mainshock and aftershock and the source spectra obtained by spectral division.

circles) is $3.0 \times 10^{15} \mathrm{~J}$ and the standard deviation is $0.9 \times$ $10^{15} \mathrm{~J}$.

Of the five EGFs, two aftershocks (19991016225341 and 19991019122044) have mechanisms that are most similar to the mainshock and are located close to the fault trace. The energy estimates obtained using these aftershocks as EGFs have the smallest scatter. The deconvolution does not work as well for the foreshock (19991016024105), because of its small size and hence low amplitude. Despite the differences in focal mechanisms of the mainshock and EGF events, the energy estimates are still clustered between $2 \times$ $10^{15} \mathrm{~J}$ and $4 \times 10^{15} \mathrm{~J}$.

As mentioned earlier, the regional source spectrum below $0.05 \mathrm{~Hz}$ is noisy. Thus, we calculate the integral of the adjusted regional source spectrum between $0.05 \mathrm{~Hz}$ and 1 $\mathrm{Hz}$. To compute energy between 0 to $0.05 \mathrm{~Hz}$, we again use a theoretical spectrum in the form $\hat{\dot{M}}(\omega)=M_{0} \omega_{\mathrm{c}}^{n} /\left(\omega^{n}+\right.$ $\omega_{\mathrm{c}}^{n}$ ) that fits the teleseismic moment-rate spectrum (the fit results in $\omega_{\mathrm{c}}=0.37 \mathrm{radians} / \mathrm{sec}$, and $\mathrm{n}=1.8$ ) and so de-

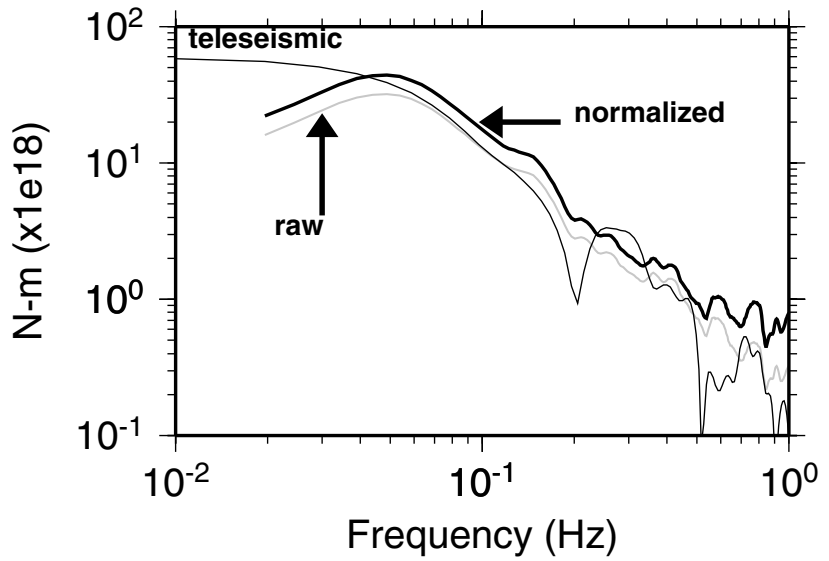

Figure 3. The average normalized source spectrum obtained by using event 19991019122044 as the EGF is shown by the thick dark line. The gray curve shows the raw source spectrum. The thin dark line represents the teleseismic moment rate spectrum obtained from Ji et al. (2002).

termine that the energy in this frequency range is only about $8 \%$ of the total energy. Using this theoretical source spectrum, we also determine that the energy at frequencies above $1 \mathrm{~Hz}$ is about $20 \%$ of the energy from the frequency band below $1 \mathrm{~Hz}$.

Equation (1) gives the radiated energy for a point source. For a finite source, the directivity effect should be removed. The Hector Mine earthquake is essentially a bilateral rupture, with a total fault length of about $40 \mathrm{~km}(\mathrm{Ji}$ et al., 2002; Treiman et al., 2002). In this case, the directivity effect is not expected to be very large and would not have a significant effect on the regional energy estimates. In fact, Figure 4 shows no obvious azimuthal variation in energy estimates. Thus, we do not make any correction for directivity. For a larger event with strong directivity, however, such as the 1992 Landers, California, earthquake (Wald and Heaton, 1994), it would be necessary to apply corrections for directivity.

The deconvolution assumes that the EGF amplitude spectra are flat in the frequency range of interest (i.e., at frequencies less than $1 \mathrm{~Hz}$ ). The EGF events used in this study are at least 2.6 magnitude units smaller than the mainshock, so their theoretical corner frequencies (using the relation $f_{\mathrm{c}}=0.49 \beta\left(\Delta \sigma / M_{0}\right)^{1 / 3}$, where $\beta=3.7 \mathrm{~km} / \mathrm{sec}, \Delta \sigma=$ $3 \mathrm{MPa}$, and $M_{0}$ is the moment) are larger than $1 \mathrm{~Hz}$. Also, our calculations show that the corner-frequency effect does not affect the energy estimates significantly.

\section{Calibration of Teleseismic Methods of Estimating Radiated Energy}

\section{Data and Method}

The teleseismic data for the Hector Mine earthquake were obtained from the IRIS Data Management Center. We use vertical-component data (BHZ channel) of stations at 
distances between $30^{\circ}$ and $90^{\circ}$ in the teleseismic study. Although $P$ waves carry only $5 \%$ of the total seismic energy, $S$ waves are more attenuated than $P$ waves, so we use Pwaves in our analysis. The energy obtained from the $P$ waves is used to estimate the total energy, using equation (1).
For a shallow event like the Hector Mine earthquake (depth $\sim 7 \mathrm{~km}$ ) (Hauksson et al., 2002), it is difficult to separate the $P, p P$, and $s P$ phases. When we study such events, we have to consider the $P$-wave group as a whole. A closer look at teleseismic displacement records (e.g., station SJG

Table 1

Mainshock and Aftershock Data

\begin{tabular}{lccccrrr}
\hline Event id & Latitude & Longitude & Depth $(\mathrm{km})$ & $M$ & Strike & Dip & Rake \\
\hline 19991016024105 & $34.59^{\circ} \mathrm{N}$ & $116.26^{\circ} \mathrm{W}$ & 4.4 & 3.7 & $77^{\circ}$ & $74^{\circ}$ & $15^{\circ}$ \\
19991016094645 & $34.59^{\circ} \mathrm{N}$ & $116.27^{\circ} \mathrm{W}$ & 6.2 & 7.1 & $330^{\circ}$ & $78^{\circ}$ & $165^{\circ}$ \\
19991016135917 & $34.83^{\circ} \mathrm{N}$ & $116.35^{\circ} \mathrm{W}$ & 4.1 & 4.4 & $257^{\circ}$ & $53^{\circ}$ & $-59^{\circ}$ \\
19991016180153 & $34.68^{\circ} \mathrm{N}$ & $116.31^{\circ} \mathrm{W}$ & 5.1 & 2.8 & $260^{\circ}$ & $68^{\circ}$ & $-32^{\circ}$ \\
19991016225341 & $34.71^{\circ} \mathrm{N}$ & $116.36^{\circ} \mathrm{W}$ & 3.1 & 4.5 & $250^{\circ}$ & $83^{\circ}$ & $-15^{\circ}$ \\
19991019122044 & $34.71^{\circ} \mathrm{N}$ & $116.34^{\circ} \mathrm{W}$ & 3.0 & 4.1 & $86^{\circ}$ & $62^{\circ}$ & $20^{\circ}$ \\
\hline
\end{tabular}

$M$ represents the local magnitude, $M_{\mathrm{L}}$, of the empirical Green's functions events or the moment magnitude, $M_{\mathrm{w}}$, of the mainshock.

(a)

19991016225341

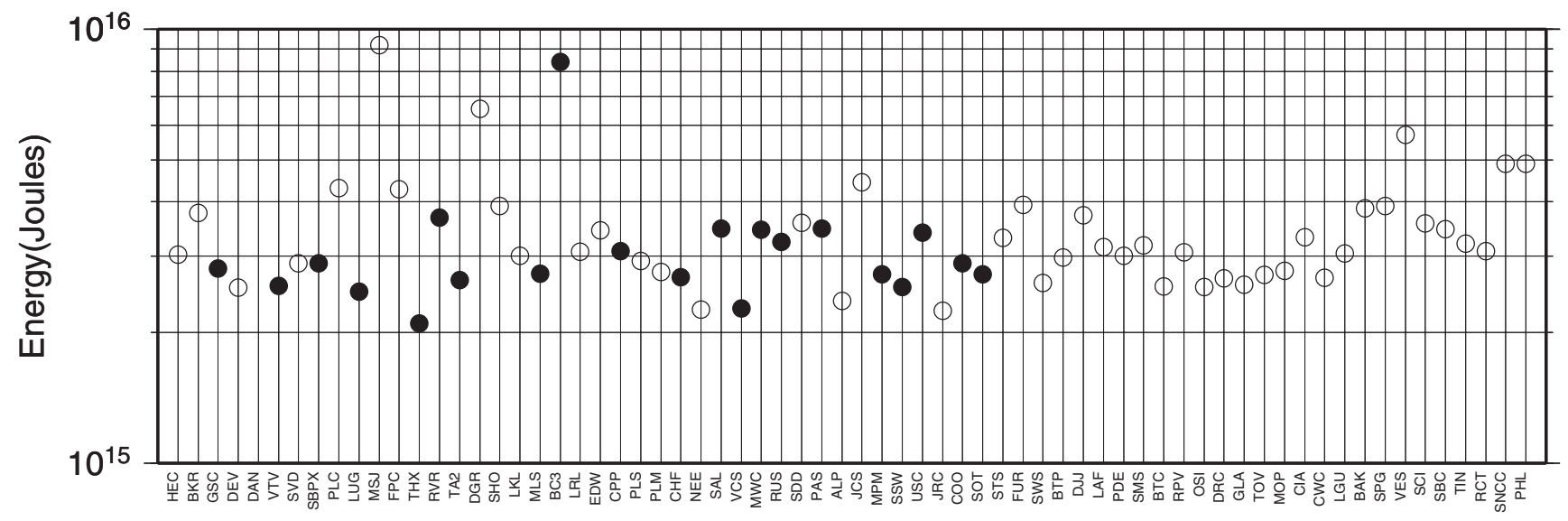

(b) $\quad 19991019122044$

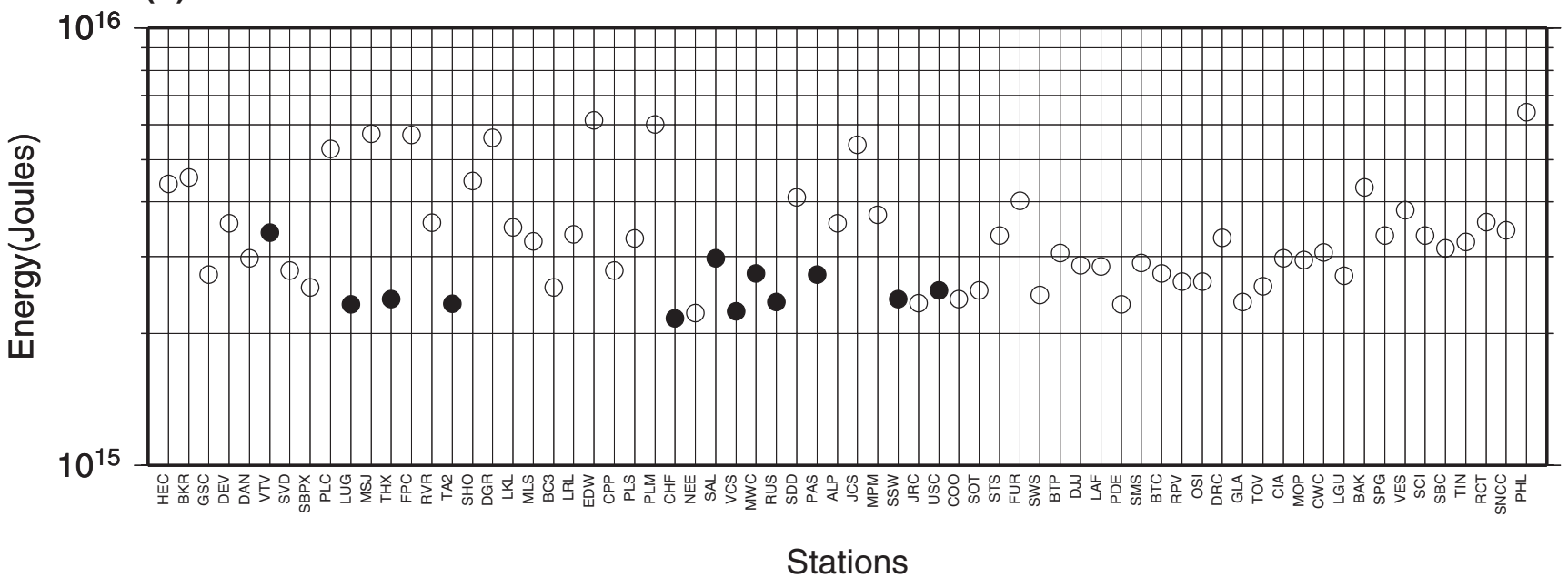

Figure 4. Results of regional estimates; each figure is a plot of the energy at different stations obtained by using different events as EGFs. (a) EGF: 19991016225341; (b) EGF: 19991019122044. (Continued on facing page.) 
(c)

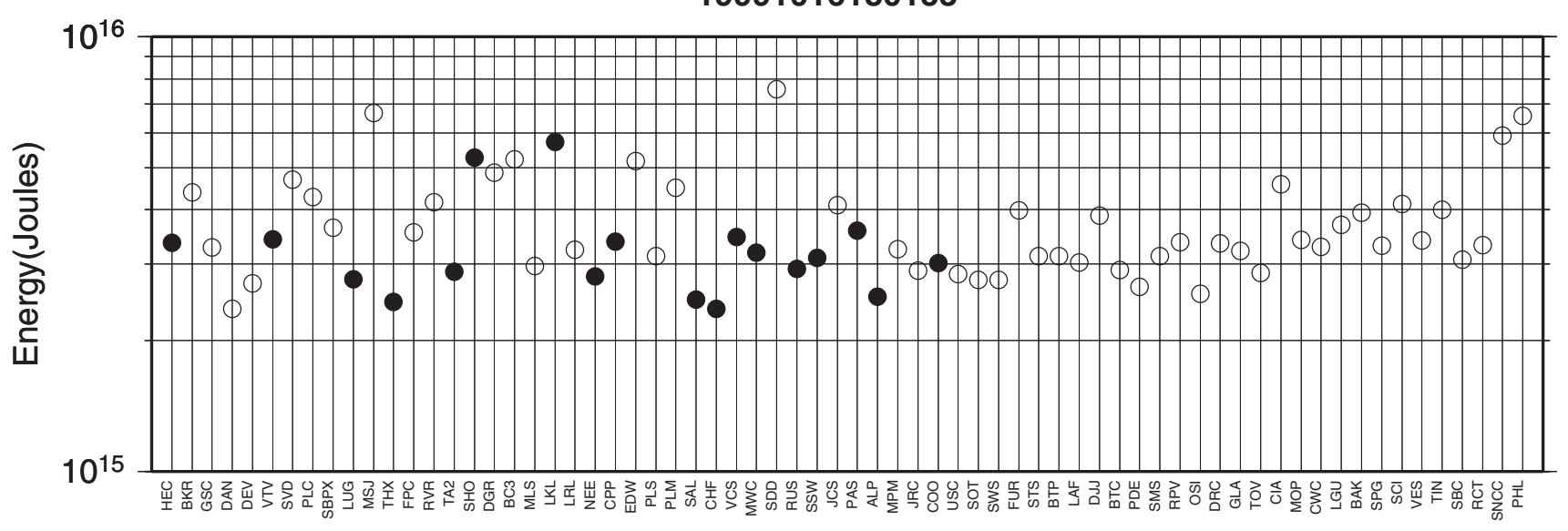

(d)

19991016024105

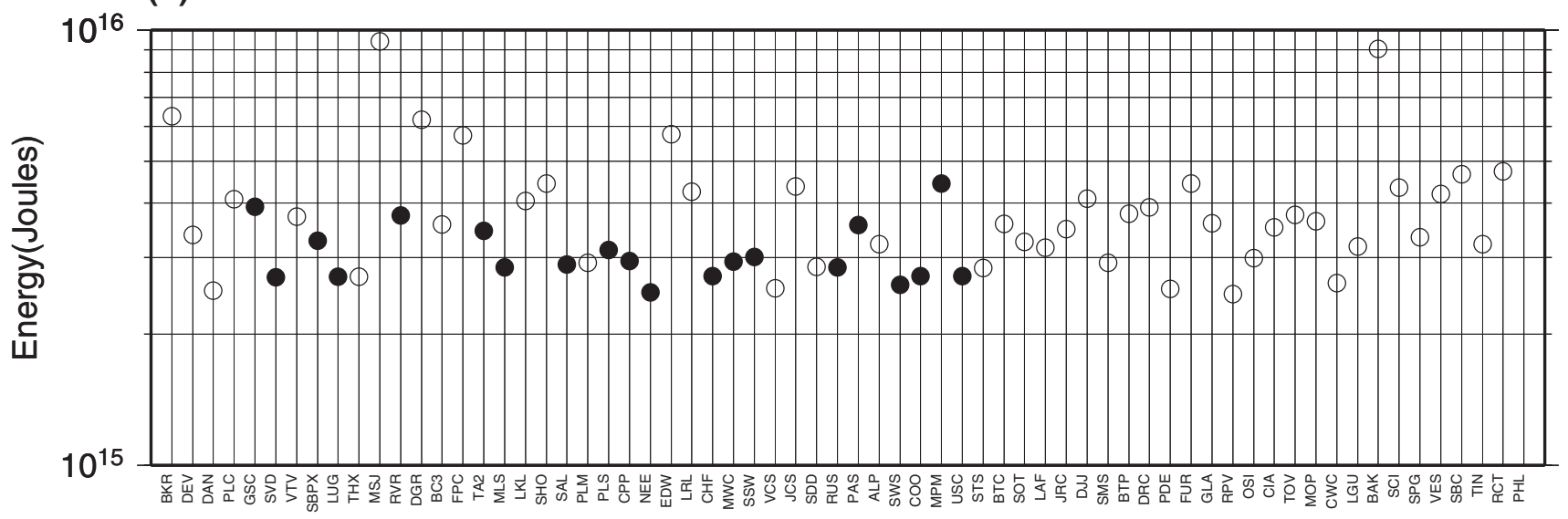

(e)

19991016135917

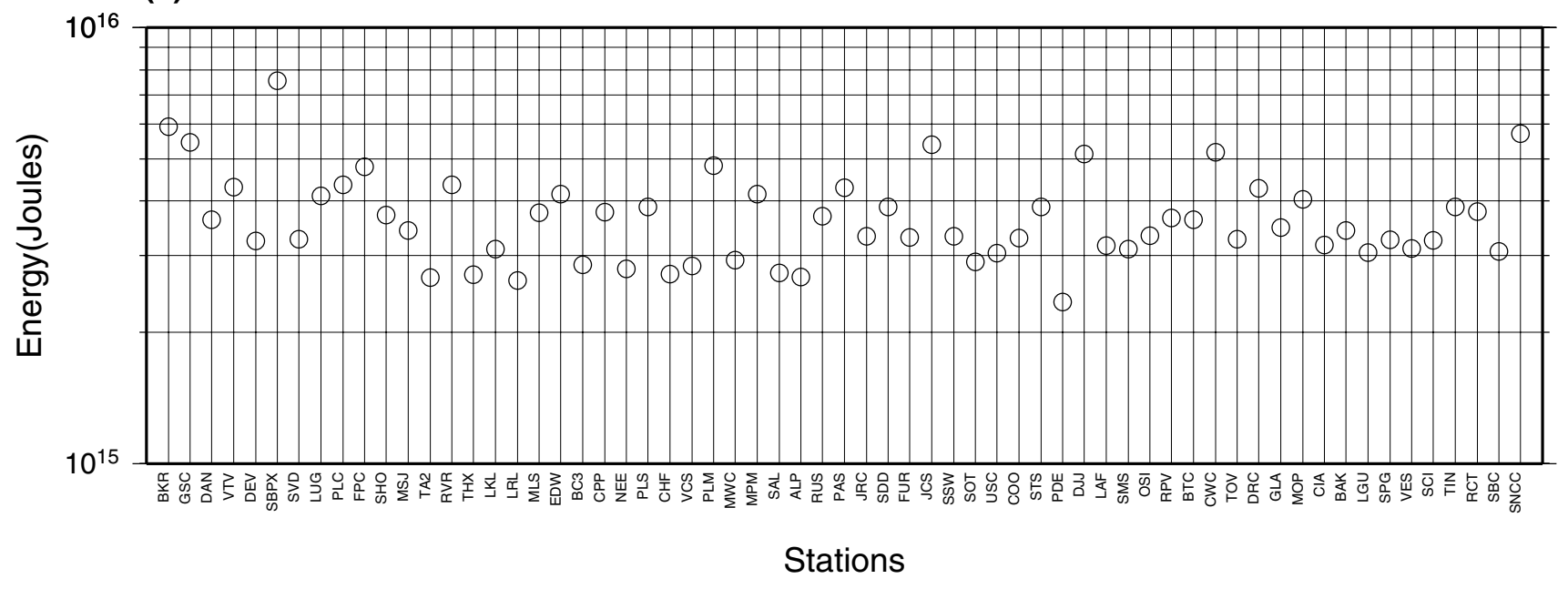

Figure 4. Results of regional estimates (continued); (c) EGF: 19991016180153; (d) EGF: 19991016024105; (e) EGF: 19991016135917. Closed circles represent stations that are within $200 \mathrm{~km}$ of the mainshock and away from the nodal planes. 
shown in Fig. 5) reveals reverberation following $s P$, which is probably caused by near-source scattering. To avoid including these scattered waves in analysis, we use only about 30 sec of data (shown in Fig. 5).

We compute the radiated energy from teleseismic data using two different methods. The first method is the conventional (NEIC) method, where the energy is computed by applying corrections to the integrated velocity spectrum (Boatwright and Choy, 1986). The amplitude spectrum of the moment-rate spectrum is determined using

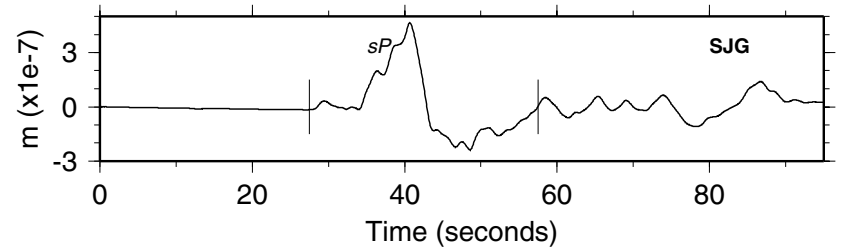

Figure 5. The $P$ group displacement record for the station SJG. The largest phase, sP, is marked. The 30 sec of data used in the actual energy computation lie within the tick marks. Scattered arrivals can be clearly observed after the sP-phase arrival.

$$
\hat{\dot{M}}(\omega) \mid=\frac{4 \pi \rho \alpha^{3} R_{\mathrm{E}} \mathrm{e}^{(\omega t * / 2)}|\hat{u}(\omega)|}{g(\Delta) R(\theta, \phi) I} .
$$

where $\hat{u}(\omega)$ is the displacement spectrum, $R_{\mathrm{E}}=6371 \mathrm{~km}$ is the radius of the earth, $t^{*}$ is the attenuation constant (equal to the travel time divided by the path-averaged $Q), g(\Delta)$ is the geometric spreading factor, $I$ is the instrument correction factor, and $R(\theta, \phi)$ is the effective radiation pattern for the $P$-wave group. $R(\theta, \phi)$ is obtained by computing the amplitudes of the $P, p P$ and $s P$ phases at each station and then taking the root-mean-square value (for a strike-slip earthquake this factor is dominated by the $s P$ radiation pattern). This method does not account for the effect of the phase differences between the $P, p P$, and $s P$ phases (Houston, 1990b).

In the second method, we compute Green's functions for the appropriate near-source structure (the eastern California velocity model; Jones and Helmberger, 1998) and deconvolve the Green's function from the mainshock data to obtain the source spectrum at each station. As the Green's functions vary with depth and the fault ruptures over a finitedepth extent, we decided to use a Green's function averaged over depth (1-7 km). Uncertainty in the near-source struc-

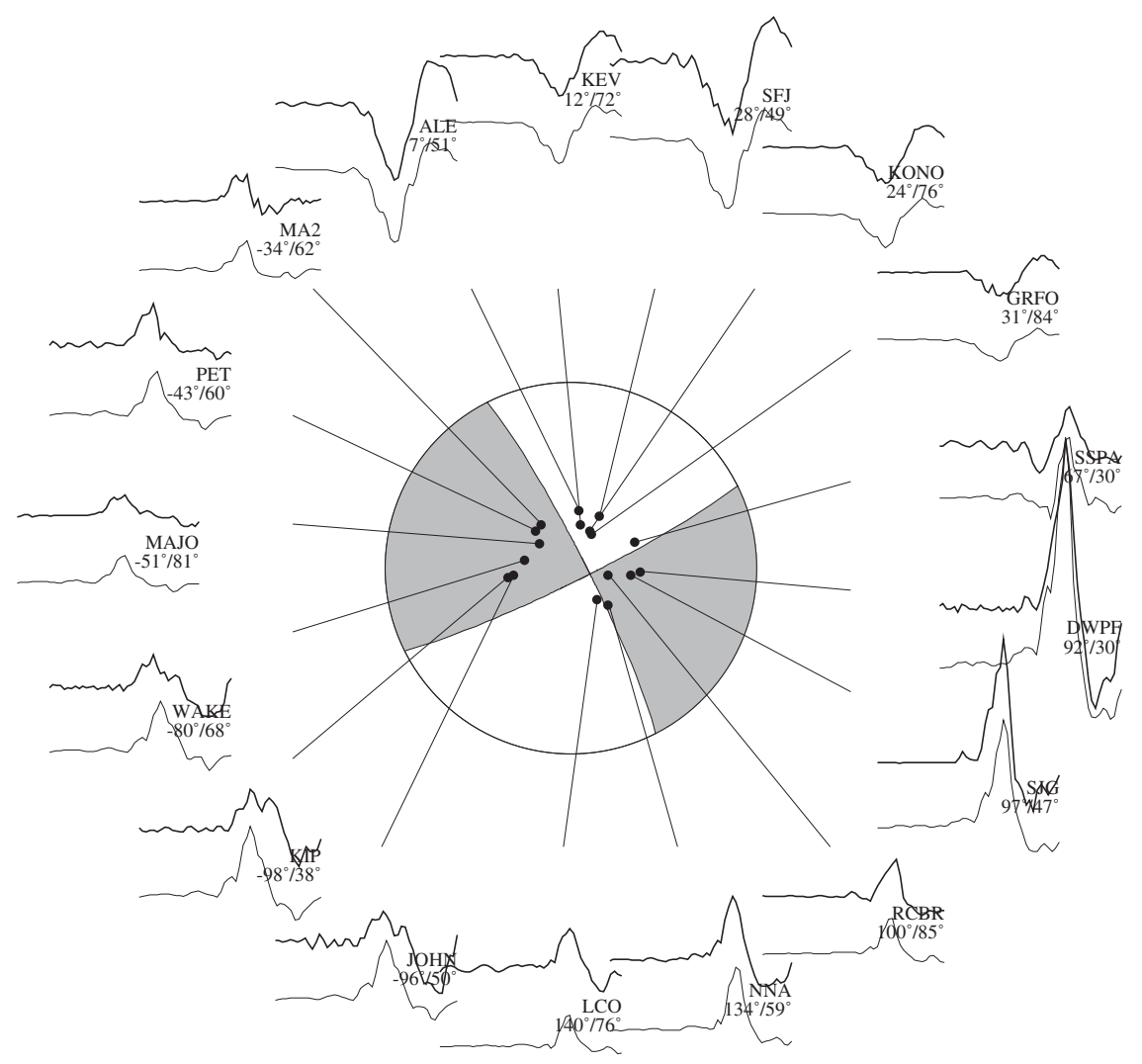

Figure 6. $\quad P$ wave focal mechanism (lower hemisphere projection), showing displacement data (top trace) and synthetics (bottom trace) at teleseismic stations. The station name and its azimuth and distance from the epicenter are shown. The synthetics are obtained by a waveform inversion (Kikuchi and Kanamori, 1991). 
ture could result in inaccurate Green's functions and hence inaccurate estimates of energy. To ensure that the structure that we use is appropriate, we perform a teleseismic inversion of the data at 37 stations using the method of Kikuchi and Kanamori (1991). Figure 6 shows the $P$-wave focal mechanism, the displacement data (top trace), and synthetics (bottom trace) at 18 of the stations used in the study. The synthetics match the data reasonably well. The teleseismic moment-rate function obtained from this inversion is very similar to that obtained by (Ji et al., 2002).

We estimate the attenuation correction using frequency dependent $t^{*}$ models that are derived from the models described in Der (1998) (see Appendix for details). As the radiation pattern for a strike-slip event is small, small changes in the mechanism can have a significant effect on the estimates of radiated energy. The radiation pattern is particularly sensitive to changes in the dip angle of the fault plane. We observe that by changing the dip from $78^{\circ}$ (the value obtained from the inversion of regional data) to $84^{\circ}$ (the value obtained from the teleseismic inversion described above), the average teleseismic estimates of radiated energy vary from $2 \times 10^{15}$ to $7 \times 10^{15} \mathrm{~J}$. Synthetics computed using these different values of dip do not differ significantly from each other.

Figure 7 shows the source spectra at station SJG corrected using method 1 and method 2. The average value of the energy estimated using the first method is $1.8 \times 10^{15} \mathrm{~J}$, and the average estimate of energy from the second method is $2.0 \times 10^{15} \mathrm{~J}$ (the mechanism we use is given in Table 1). Figure 8 shows the energy estimates at 14 stations using method 1 (open diamonds) and method 2 (closed circles).

\section{Discussion and Conclusions}

Earlier estimates of radiated energy from regional data of other earthquakes were obtained by the integration of

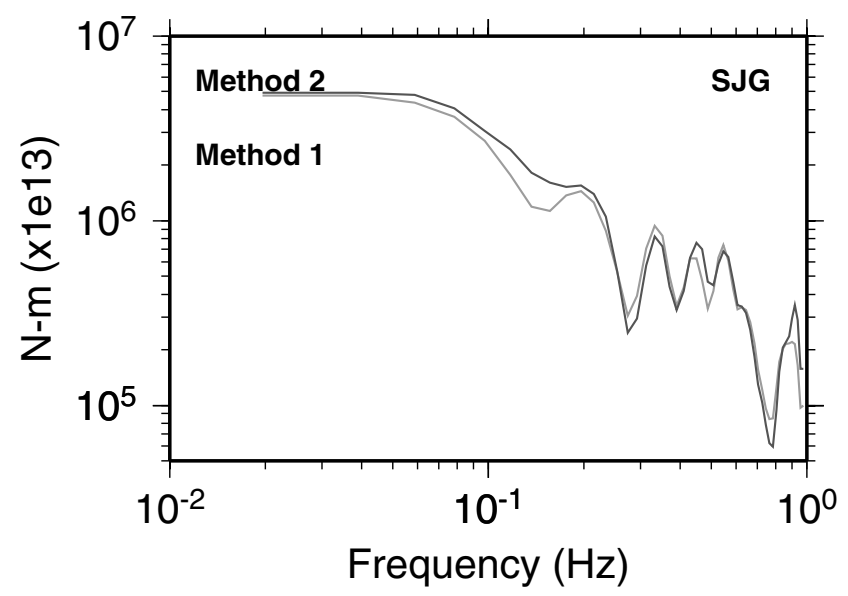

Figure 7. The teleseismic moment-rate spectrum obtained at station SJG using methods 1 and 2 (see text). squared ground-motion velocity records (or integration of ground-motion velocity spectra) and application of empirical distance, attenuation and station corrections (Kanamori et al., 1993; Singh and Ordaz, 1994). Another method, which uses coda waves to determine radiated energy (Mayeda and Walter, 1996), also applies empirical corrections to remove near-site attenuation and amplification effects. The Hector Mine earthquake is unique in that both the mainshock and aftershock data are very well recorded and hence we can use an empirical Green's function method to determine the source spectrum. This method corrects for attenuation and site effects through the use of smaller events as empirical Green's functions; thus, we have robust estimates of energy from the source spectrum of the regional data.

The teleseismic energy estimates show a large scatter and are less reliable than the regional estimates. There are several difficulties in estimating energy from teleseismic data. The attenuation along the path from the source to the receiver is not well determined; near-source structure is poorly determined, resulting in inaccurate corrections for the structural effects. Additionally, strike-slip earthquakes have small radiation pattern coefficients, and hence small differences in the radiation pattern factor (due to differences in the focal mechanism) can result in large differences in energy estimates. In this study, we obtain a mean estimate of energy from teleseismic data of $1.8 \times 10^{15} \mathrm{~J}$ and $2.0 \times 10^{15}$ $\mathrm{J}$ using two different teleseismic methods; these estimates are almost the same as that obtained from regional data (3 $\times 10^{15} \mathrm{~J}$ ). These estimates of radiated energy for the Hector Mine earthquake are in agreement with the values obtained by Boatwright et al. (2002).

From the regional estimates of radiated energy $(3 \times$ $\left.10^{15} \mathrm{~J}\right)$ and teleseismic inversions for the moment $\left(6 \times 10^{19}\right.$ $\mathrm{Nm})$, the energy-to-moment ratio $\left(E_{\mathrm{R}} / M_{0}\right)$ for the Hector Mine earthquake is $5 \times 10^{-5}$. Figure 9 shows the results from several regional studies. The energy-to-moment ratio is shown as a function of moment magnitude, $M_{\mathrm{w}}$. The black circle represents the $E_{\mathrm{R}} / M_{0}$ ratio of the Hector Mine earthquake. The difference in the ratio between large and small earthquakes has been used by Kanamori and Heaton (2000) and by Brodsky and Kanamori (2001) to argue that, when the slip exceeds a threshold of $10 \mathrm{~cm}$ to $1 \mathrm{~m}$, the frictional characteristics on the fault plane undergo a significant change because of processes such as melting, thermal pressurization, or elastohydrodynamic lubrication. However, these arguments rely on the accuracy of estimates of $E_{R} / M_{0}$. The current estimates of $E_{R} / M_{0}$ are scattered over a large range as shown in Figure 9 and this scatter may be due to inaccurate estimates of radiated energy. As we have demonstrated above, the regional estimates of radiated energy for the Hector Mine earthquake are robust and constitute an important data point for studies involving the radiated energy. Also, this event could serve as a calibration for future studies of radiated energy. 


\section{Hector}

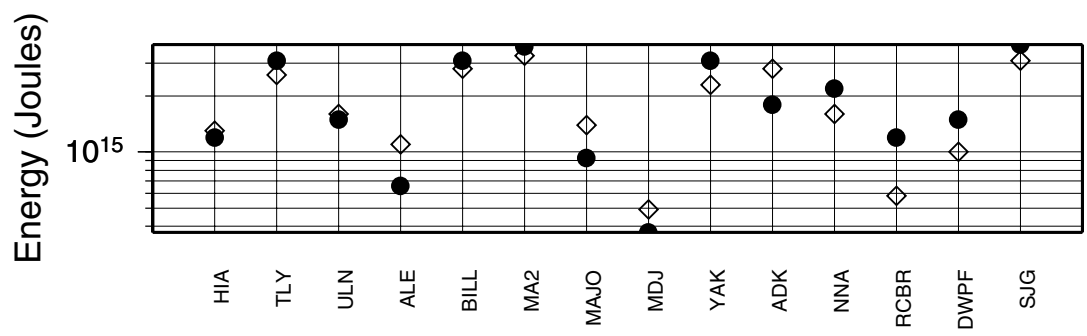

Stations

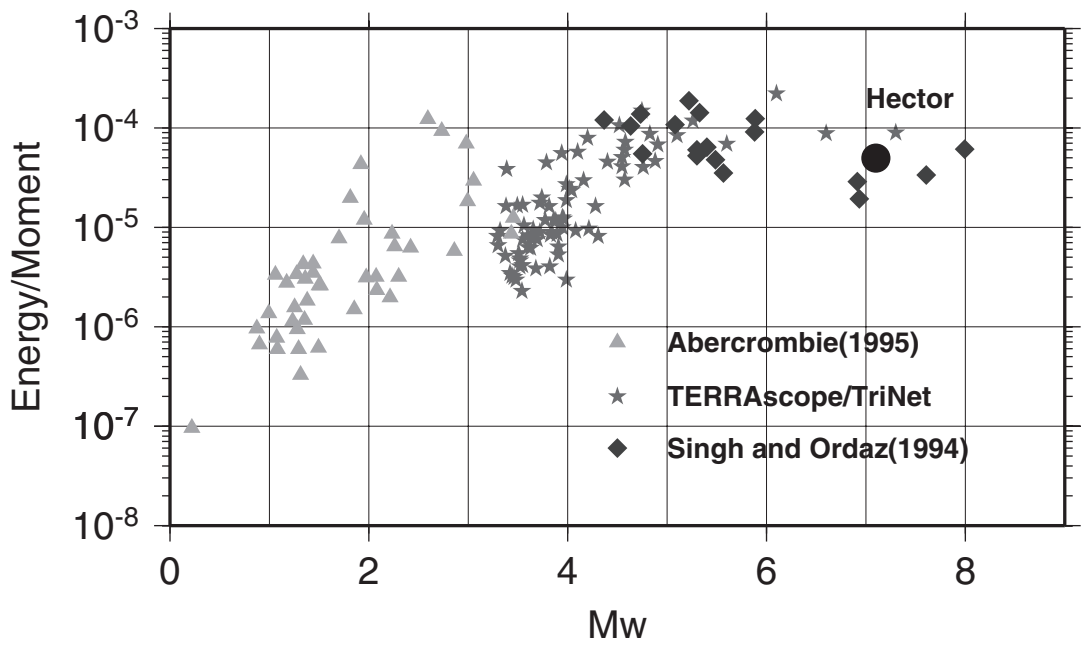

Figure 8. Radiated energy at teleseismic stations. Open diamonds represent the energy estimates obtained using method 1; closed circles represent the estimates obtained using method 2 .
Figure 9. Energy to moment ratio $\left(E_{\mathrm{s}} / M_{0}\right)$ as a function of $M_{\mathrm{w}}$. The plot shows the results of regional studies conducted for different earthquakes by several investigators. Triangles represent a study by Abercrombie (1995), stars represent the study using TERRAscope/TriNet data (Kanamori et al., 1993), and diamonds represent a study by Singh and Ordaz (1994). The black circle shows our result for the Hector Mine earthquake.

\section{Acknowledgments}

We thank Dr. Yoshiaki Hisada for the code used to compute Green's functions for stations and receivers close to the surface, Egill Hauksson for the Hector Mine earthquake catalog, and Lupei Zhu for the focal mechanism solutions of the mainshock and EGFs. We are grateful to Jeroen Ritsema for his help with the seismic tomographic model. We also thank $\mathrm{J}$. Boatwright and S. K. Singh for their comments and suggestions to improve the manuscript. This study was partially supported by the United States Geological Survey Grant Number 99HQGR0035 and NSF Grant Number NSF-EAR-9909371. Contribution Number 8761 of the Division of Geological and Planetary Sciences, California Institute of Technology.

\section{References}

Abercrombie, R. (1995). Earthquake source scaling relationships from -1 to $5 M_{\mathrm{L}}$ using seismograms recorded at $2.5-\mathrm{km}$ depth, J. Geophys. Res. 100, 24,015-24,036.

Archambeau, C. B., E. A. Flinn, and D. G. Lambert (1969). Fine structure of the upper mantle, J. Geophys. Res. 74, 5825-5865.

Boatwright, J., and G. L. Choy (1986). Teleseismic estimates of the energy radiated by shallow earthquakes, J. Geophys. Res. 91, 2095-2112.

Boatwright, J., and M. Cocco (1996). Frictional constraints on crustal faulting, J. Geophys. Res. 101, 13,895-13,909.

Boatwright, J., and J. B. Fletcher (1984). The partition of radiated energy between $P$ and $S$ waves, Bull. Seism. Soc. Am. 74, 361-376.

Boatwright, J., G. L. Choy, and L. C. Seekins (2002). Regional estimates of radiated seismic energy, Bull. Seism. Soc. Am. 92, 1241-1255 (this issue).
Brodsky, E. E., and H. Kanamori (2001). The elastohydrodynamic lubrication of faults, J. Geophys. Res. 106, 16,357-16,375.

Choy, G. L., and J. L. Boatwright (1995). Global patterns of radiated energy and apparent stress, J. Geophys. Res. 100, 18,205-18,228.

Der, Z. A. (1998). High frequency $P$ - and $S$-wave attenuation in the earth, Pageoph 153, 273-310.

Frankel, A., and H. Kanamori (1983). Determination of rupture duration and stress drop for earthquakes in southern California, Bull. Seism. Soc. Am. 73, 1527-1551.

Guatteri, M., and P. K. P. Spudich (2000). What can strong-motion data tell us about slip-weakening fault-friction laws?, Bull. Seism. Soc. Am. 90, 98-116.

Gutenberg, B. (1942). Earthquake magnitude, intensity, energy, and acceleration, Bull. Seism. Soc. Am. 32, 163-191.

Gutenberg, B., and C. F. Richter (1956a). Earthquake magnitude, intensity, energy, and acceleration, Bull. Seism. Soc. Am. 46, 105-145.

Gutenberg, B., and C. F. Richter (1956b). Magnitude and energy of earthquakes, Ann. Geofis. (Rome) 9, 1-15.

Hartzell, S. (1978). Earthquake aftershocks as Green's functions, Geophys. Res. Lett. 5, 1-4.

Haskell, N. (1964). Total energy and energy spectral density of elastic wave radiation from propagating faults, Bull. Seism. Soc. Am. 56, 18111842.

Hauksson, E., L. M. Jones, and L. K. Hutton (2002). The $1999 M_{\mathrm{w}} 7.1$ Hector Mine, California, earthquake sequence: complex conjugate strike-slip faulting, Bull. Seism. Soc. Am. 92, 1154-1170 (this issue).

Hisada, Y. (1994). An efficient method for computing Green's functions for a layered half-space with sources and receivers at close depths, Bull. Seism. Soc. Am. 84, 1456-1472. 
Houston, H. (1990a). Broadband source spectrum, seismic energy, and stress drop of the 1989 Macquarie Ridge earthquake, Geophys. Res. Lett. 17, 1021-1024.

Houston, H. (1990b). A comparison of broadband source spectra, seismic energies, and stress drops of the 1989 Loma Prieta and 1988 Armenian earthquakes, Geophys. Res. Lett. 17, 1413-1416.

Houston, H., and H. Kanamori (1990). Comparison of strong motion spectra with teleseismic spectra for three magnitude 8 subduction-zone earthquakes, Bull. Seism. Soc. Am. 80, 913-934.

Ide, S., and M. Takeo (1997). Determination of constitutive relations of fault slip based on seismic wave analysis, J. Geophys. Res. 102, 27,379-27,391.

Ji, C., D. J. Wald, and D. V. Helmberger (2002). Source description of the 1999 Hector Mine, California earthquake. II. Complexity of slip history, Bull. Seism. Soc. Am. 92, 1208-1226 (this issue).

Jones, L., and D. V. Helmberger (1998). Earthquake source parameters and fault kinematics in the eastern California shear zone, Bull. Seism. Soc. Am. 88, 1337-1352.

Kanamori, H., and T. Heaton (2000). Microscopic and macroscopic mechanisms of earthquakes, in GeoComplexity and the Physics of Earthquakes, J. B. Rundle, D. L. Turcotte, and W. Klein (Editors) American Geophysical Monograph 120, 147-163.

Kanamori, H., E. Hauksson, L. K. Hutton, and L. M. Jones (1993). Determination of earthquake energy release and $M_{\mathrm{L}}$ using TERRAscope, Bull. Seism. Soc. Am. 83, 330-346.

Kikuchi, M., and Y. Fukao (1988). Seismic wave energy inferred from long-period body wave inversion, Bull. Seism. Soc. Am. 78, 17071724.

Kikuchi, M., and H. Kanamori (1991). Inversion of complex body waves. III. Bull. Seism. Soc. Am. 81, 2335-2350.

Mayeda, K., and W. R. Walter (1996). Moment, energy, stress drop, and source spectra of western United States earthquakes from regional coda envelopes, J. Geophys. Res. 101, 11,195-11,208.

Mori, J. (1993). Fault plane determinations for three small earthquakes along the San Jacinto fault, California: search for cross faults, J. Geophy. Res. 98, 17,711-17,722.

Mori, J., and A. Frankel (1990). Source parameters for small events associated with the 1986 North Palm Springs, California, earthquake determined using empirical Green functions, Bull. Seism. Soc. Am. 80, 278-295.

Mori, J., H. Kanamori, J. Davis, E. Hauksson, R. Clayton, T. Heaton, L. Jones, and A. Shakal (1998). Major improvements in progress for southern California earthquake monitoring, EOS Trans. Am. Geophys. Union 79, 217-221.

Pulido, N., and K. Irikura (2000). Estimation of dynamic rupture parameters from the radiated seismic energy and apparent stress, Geophys. Res. Lett. 27, 3945-3948.

Ritsema, J., H. J. van Heijst, and J. Woodhouse (1999). Complex shear wave velocity structure imaged beneath Africa and Iceland, Science 286, 1925-1928.

Singh, S. K., and M. Ordaz (1994). Seismic energy release in Mexican subduction zone earthquakes, Bull. Seisml. Soc. Am. 84, 1533-1550.

Treiman, J. A., K. J. Kendrick, W. A. Byrant, T. K. Rockwell, and S. F. McGill (2002). Primary surface rupture associated with the $M_{\mathrm{w}} 7.1$ 16 October 1999 Hector Mine earthquake, San Bernardino County, California, Bull. Seism. Soc. Am. 92, 1171-1191 (this issue).

Vassiliou, M. S., and H. Kanamori (1982). The energy release in earthquakes, Bull. Seism. Soc. Am. 72, 371-387.

Wald, D. J., and T. H. Heaton (1994). Spatial and temporal distribution of slip for the 1992 Landers, California, earthquake, Bull. Seism. Soc. Am. 84, 668-691.

Winslow, N. W., and L. J. Ruff (1999). A hybrid method for calculating the radiated wave energy of deep earthquakes, Phys. Earth Planet. Inter. 115, 181-190.

Wyss, M., and J. Brune (1971). Regional variations of source properties in southern California estimated from the ratio of short- to long-period amplitudes, Bull. Seism. Soc. Am. 61, 1153-1168.

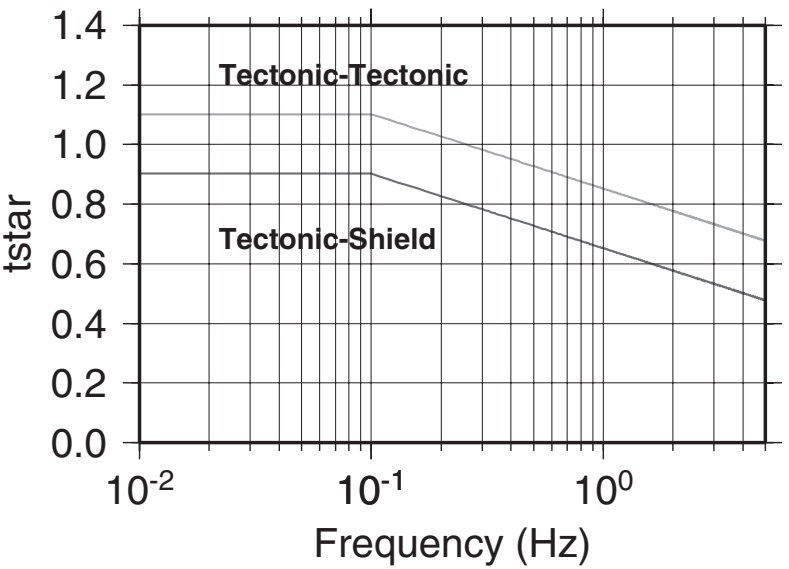

Figure A1. $\quad t^{*}$ models: the variation of $t^{*}$ with frequency for tectonic and shield stations at a distance of $50^{\circ}$ from the source. We also include a slight distance dependence of $t^{*}$; for tectonic stations $t^{*}$ varies from 0.87 at $30^{\circ}$ to 0.79 at $90^{\circ}$, whereas for shield stations $t^{*}$ varies from 0.67 at $30^{\circ}$ to 0.59 at $90^{\circ}$.

\section{Appendix \\ On Attenuation Correction}

To estimate the attenuation correction, we use frequency dependent $t^{*}$ models derived from the models described in Der (1998). Here, we briefly outline the procedure we use to determine the $t^{*}$ models. Because attenuation of seismic energy is dominated by near-surface effects, we decide to broadly account for the differences in the crustal structure beneath seismic stations. We divide all the teleseismic stations into two categories, shield stations and tectonic stations, based on a seismic tomography model (S20RTS) (Ritsema et al., 1999). Stations that lie within regions $4 \%$ faster than PREM at $120 \mathrm{~km}$ are defined as shield stations; all other stations are tectonic. For the shield stations, we use the QP S-T model of Der (1998); for the tectonic stations, we use a model obtained by combining the QP S-T and QP S-S models. The long-period $t^{*}$ at each station is determined by using the velocity and $Q$ structure for the western United States given by Archambeau et al. (1969). Using this initial $t^{*}$ and the appropriate frequency-dependent $t^{*}$ model, we apply a frequency-dependent $t^{*}$ correction at each station (see Fig. A1).

Seismological Laboratory

California Institute of Technology

Mail Code 252-21

1200 E. California Blvd.

Pasadena, California 91125

anupama@gps.caltech.edu

(A.V., H.K.)

École et Observatoire des Sciences de la Terre

5 , rue René Descartes

67084 Strasbourg cedex

France

(L.R.)

Manuscript received 3 April 2001. 